\title{
A novel whole-cell lysate kinase assay identifies substrates of the p38 MAPK in differentiating myoblasts
}

\author{
James DR Knight ${ }^{1,2,9}$, Ruijun Tian ${ }^{3,4,9}$, Robin EC Lee ${ }^{1,2,10}$, Fangjun Wang ${ }^{3,5}$, Ariane Beauvais ${ }^{1}$, Hanfa Zou ${ }^{5}$, \\ Lynn A Megeney ${ }^{1,2,6}$, Anne-Claude Gingras ${ }^{7,8}$, Tony Pawson ${ }^{7,8}$, Daniel Figeys ${ }^{3,4}$ and Rashmi Kothary ${ }^{1,2,6^{*}}$
}

\begin{abstract}
Background: The p38 $\alpha$ mitogen-activated protein kinase (MAPK) is a critical mediator of myoblast differentiation, and does so in part through the phosphorylation and regulation of several transcription factors and chromatin remodelling proteins. However, whether p38 $\alpha$ is involved in processes other than gene regulation during myogenesis is currently unknown, and why other p38 isoforms cannot compensate for its loss is unclear.

Methods: To further characterise the involvement of p38 $\alpha$ during myoblast differentiation, we developed and applied a simple technique for identifying relevant in vivo kinase substrates and their phosphorylation sites. In addition to identifying substrates for one kinase, the technique can be used in vitro to compare multiple kinases in the same experiment, and we made use of this to study the substrate specificities of the p38 $\alpha$ and $\beta$ isoforms.

Results: Applying the technique to $p 38 \alpha$ resulted in the identification of seven in vivo phosphorylation sites on six proteins, four of which are cytoplasmic, in lysate derived from differentiating myoblasts. An in vitro comparison with p38 $\beta$ revealed that substrate specificity does not discriminate these two isoforms, but rather that their distinguishing characteristic appears to be cellular localisation.

Conclusion: Our results suggest p38 $\alpha$ has a novel cytoplasmic role during myogenesis and that its unique cellular localisation may be why p38 $\beta$ and other isoforms cannot compensate for its absence. The substrate-finding approach presented here also provides a necessary tool for studying the hundreds of protein kinases that exist and for uncovering the deeper mechanisms of phosphorylation-dependent cell signalling.
\end{abstract}

Keywords: differentiation, FSBA, kinase assay, mitogen-activated protein kinase, myoblast, p38, phosphorylation, quantitative MS

\section{Background}

Protein kinases are well-known regulators of cell signalling and cellular behaviour that execute their function through the covalent attachment of an ATP-derived phosphate to protein substrates. To understand the function of any protein kinase on a large and cell-wide scale first requires the development of a substrate screening technique that allows for the proteins phosphorylated by a kinase of interest to be comprehensively identified, ideally in a single experiment. Although

\footnotetext{
* Correspondence: rkothary@ohri.ca

${ }^{1}$ Regenerative Medicine Program, Ottawa Hospital Research Institute, 501

Smyth Road, Ottawa, ON, K1H 8L6, Canada

Full list of author information is available at the end of the article
}

substrate-finding techniques exist, they are hindered by problems that prevent them from being easily or readily employed [1-4] and are generally limited to providing in vitro substrate identifications that may or may not be relevant in vivo. In vivo approaches currently available, such as that employed by Holt et al. [5], can associate a kinase with in vivo phosphorylation events, but direct phosphorylation cannot be inferred without additional experimentation. A simple technique that can identify direct in vivo substrates is an obvious need for the field.

The mitogen-activated protein kinase $\mathrm{p} 38 \alpha$ is involved in several cellular processes, but its critical role during differentiation, and particularly the differentiation of myoblasts, has been a major focus. At the initiation of 
myoblast differentiation, $\mathrm{p} 38 \alpha$ is known to phosphorylate several transcription factors and chromatin remodelling proteins, thereby inducing the expression of a myogenic gene program [6]. Although much is known about p38 $\alpha$ 's role in this process, it is likely very partial, and whether $\mathrm{p} 38 \alpha$ plays an important role in other processes during myoblast differentiation, such as cell fusion or sarcomere formation, is unknown. At the same time, there are questions regarding the other p38 isoforms and their role, or lack thereof, in myogenesis. p38 $\beta$ is also expressed in myoblasts and is activated in the same manner as $\mathrm{p} 38 \alpha$, but despite having a kinase domain $75 \%$ identical to that of $\mathrm{p} 38 \alpha$ ( $72 \%$ sequence identity overall), p38 $\beta$ is unable to compensate for the loss of p38 $\alpha$, even when overexpressed [7-9]. The obvious and suspected explanation is that there are critical myogenic phosphorylations specific to the $\alpha$ isoform, but these have yet to be discovered and whether this assumption is correct is unknown.

Here we describe a simple approach for substrate finding that can be used to identify in vitro and in vivo substrates. The technique begins with treatment of cell lysate to inactivate endogenous kinases, followed by an in vitro assay using an exogenous kinase of interest, and concludes with quantitative mass spectrometry (MS) to identify phosphorylation sites specific to the added kinase. By using lysate derived from vehicle- or inhibitor-treated cells, this in vitro approach can be simultaneously coupled with biologically relevant information to identify direct substrates regulated by the kinase of interest in vivo. Applying this technique to $\mathrm{p} 38 \alpha$ with lysate from differentiating myoblasts resulted in the identification of several new in vivo substrates that suggest novel functions for $\mathrm{p} 38 \alpha$ during myogenesis. We did not identify a single phosphorylation specific to the p38 $\alpha$ isoform compared with p38 $\beta$, at least in terms of in vitro substrate specificity, but we did see a clear difference in cellular localisation during myoblast differentiation. This leads us to propose that although the kinase domains of $\mathrm{p} 38 \alpha$ and $\beta$ likely have the same capacity to phosphorylate substrates, there are major differences in actual substrate specificity in an in vivo context.

\section{Methods}

\section{Cell culture}

C2C12 cells were grown in Dulbecco's modified Eagle's medium (DMEM) supplemented with 10\% (vol/vol) foetal bovine serum with $100 \mathrm{U} / \mathrm{ml}$ penicillin, $100 \mu \mathrm{g} / \mathrm{ml}$ streptomycin and $250 \mathrm{ng} / \mathrm{ml}$ amphotericin B. To induce differentiation, cells were grown to $85-90 \%$ confluence, and the medium was changed to DMEM with $2 \%$ horse serum supplemented with penicillin, streptomycin and amphotericin B as described above. FLAG-tagged p38 $\alpha$ and p38 $\beta$ were acquired from Addgene (Cambridge, MA, USA) [10]. Constructs were transfected into C2C12 myoblasts with Lipofectamine 2000 reagent (Invitrogen, Carlsbad, CA, USA) according to the manufacturer's instructions. To inhibit p38 activity, SB 202190 (Promega, Madison, WI, USA) solubilised in dimethyl sulphoxide (DMSO) or DMSO as control was added to differentiation media at 48 hours following the induction of differentiation, and medium with inhibitor was changed daily.

\section{Immunofluorescence}

Cells were fixed with $4 \%$ formaldehyde and stained with the following antibodies: Flag M2 (1:1,000 dilution; Sigma-Aldrich, St Louis, MO, USA), myosin heavy chain (MyHC) (1:20 dilution; Developmental Studies Hybridoma Bank, Department of Biology, University of Iowa, Iowa City, IA, USA), Alexa Fluor 488 goat anti-mouse antibody (1:1,000 dilution; Molecular Probes/Invitrogen) and Alexa Fluor 555 goat anti-mouse antibody (1:1,000 dilution; Molecular Probes/Invitrogen). The differentiation index was calculated as the number of MyHC-positive nuclei divided by the total number of nuclei. The fusion index was quantified as the number of nuclei per MyHC-positive cell. Five fields of view at $\times 20$ magnification were counted and averaged per replicate, with a total of three replicate experiments.

\section{Statistical analysis}

Statistical analyses were performed using StatPlus software (AnalystSoft Inc; http://www.analystsoft.com/en/ products/statplus/). The data shown are means with SD, and Student's $t$-tests were performed to determine significance for the differentiation and fusion indices.

\section{Western blot analysis}

For Western blot analysis, cells were lysed in radioimmunoprecipitation assay (RIPA) buffer $(50 \mathrm{mM}$ Tris. $\mathrm{HCl}, \mathrm{pH}$ 7.5, 1\% Nonidet P-40, 0.1\% SDS, $150 \mathrm{mM}$ $\mathrm{NaCl}, 1 \mathrm{mM}$ ethylenediaminetetraacetic acid (EDTA), 50 $\mathrm{mM} \mathrm{NaF}, 200 \mu \mathrm{M} \mathrm{Na} \mathrm{VO}_{4}, 1 \mathrm{mM}$ phenylmethanesulphonylfluoride (PMSF), $10 \mu \mathrm{g} / \mathrm{ml}$ aprotinin, $10 \mu \mathrm{g} / \mathrm{ml}$ leupeptin and $10 \mu \mathrm{g} / \mathrm{ml}$ pepstatin), and $5 \times$ Laemmli buffer (300 mM Tris, pH 6.8, 0.01\% bromophenol blue, $10 \%$ SDS, $50 \%$ glycerol and $5 \% \beta$-mercaptoethanol) was added to $25 \mu \mathrm{g}$ of protein per sample to a final concentration of $1 \times$ for SDS-PAGE. For fractionation, cells were lysed in hypotonic buffer (10 mM 4-(2-hydroxyethyl)-1-piperazineethanesulphonic acid (HEPES), $\mathrm{pH}$ 7.5, $1.5 \mathrm{mM} \mathrm{MgCl}_{2}, 10 \mathrm{mM} \mathrm{KCl}, 0.5 \mathrm{mM}$ dithiothreitol (DTT), $50 \mathrm{mM} \mathrm{NaF}, 200 \mu \mathrm{M} \mathrm{Na}_{3} \mathrm{VO}_{4}, 1 \mathrm{mM}$ PMSF, 10 $\mu \mathrm{g} / \mathrm{ml}$ aprotinin, $10 \mu \mathrm{g} / \mathrm{ml}$ leupeptin and $10 \mu \mathrm{g} / \mathrm{ml}$ pepstatin) and left on ice for 10 minutes. Cells were then passed through a 25-gauge needle three times and 
centrifuged at $500 \mathrm{~g}$ to pellet nuclei and unlysed cells. The supernatant was collected as whole cytoplasm. For further fractionation of the cytoplasm, the supernatant was centrifuged again at 5,000 $g$ to pellet mitochondria and membrane fractions. The supernatant was then collected and centrifuged at 100,000 $g$ to pellet any remaining cell particles, and the resulting supernatant was collected as cytosol. RIPA buffer was added to all fractions to a final concentration of $1 \times$ for complete lysis. Recombinant phosphorylated $\mathrm{p} 38 \alpha$ (Millipore, Billerica, MA, USA) was dephosphorylated using $\lambda$-protein phosphatase (New England Biolabs, Inc, Ipswich, MA, USA) by adding $800 \mathrm{U}$ of phosphatase to $200 \mathrm{ng}$ of p38 $\alpha$ diluted in $\lambda$-phosphatase buffer, and the sample was assayed at $30^{\circ} \mathrm{C}$ for 1 hour. Antibodies used for blotting were as follows: $\alpha$-actinin (1:125 dilution; Abcam, Cambridge, MA, USA), COX IV (1:1,000 dilution; Abcam), GRP78 (1:500 dilution; Cell Signaling Technology, Danvers, MA, USA), lamin A/C (1:500 dilution; Abcam), MyHC (1:100 dilution; Developmental Studies Hybridoma Bank), MyoD (1:1,000 dilution; Santa Cruz Biotechnology, Santa Cruz, CA, USA), myogenin (1:100 dilution; Developmental Studies Hybridoma Bank), neural cell adhesion molecule (1:200 dilution; Abcam), p38 $\alpha$ (1:500 dilution; Cell Signaling Technology), phospho-p38 (1:500 dilution; Abcam) and $\beta$-tubulin (1:1,000 dilution; Developmental Studies Hybridoma Bank). An Alpha Innotech HD2 imaging system (R\&D Systems, Minneapolis, MN, USA) was used to quantify phosphop38 and tubulin expression.

\section{FSBA treatment and substrate labelling}

Cells were lysed in Nonidet P-40 buffer $(50 \mathrm{mM}$ Tris. $\mathrm{HCl}, \mathrm{pH} 7.8,150 \mathrm{mM} \mathrm{NaCl}, 1 \%$ (vol/vol) Nonidet P-40, $1 \mathrm{mM}$ PMSF, $10 \mu \mathrm{g} / \mathrm{ml}$ aprotinin, $10 \mu \mathrm{g} / \mathrm{ml} \mathrm{leu-}$ peptin and $10 \mu \mathrm{g} / \mathrm{ml}$ pepstatin). Lysate was treated at a concentration of $2 \mathrm{mg} / \mathrm{ml}$ with $20 \mathrm{mM}$ 5'-4-fluorosulphonylbenzoyladenosine (FSBA) solubilised in DMSO and placed at $30^{\circ} \mathrm{C}$ for 1 hour. The sample was then diluted down to 1:5 with Nonidet P-40 buffer minus protease inhibitors and desalted using Millipore Amicon ultrafiltration columns with a $10 \mathrm{kDa}$ molecular weight cutoff. Following concentration, the sample was diluted to $4 \mathrm{mg} / \mathrm{ml}$ with Nonidet P-40 buffer and diluted 1:2 with $2 \times$ kinase assay buffer (40 mM 3-morpholinopropane-1-sulphonic acid (MOPS), pH 7.2, $50 \mathrm{mM} \beta$-glycerophosphate, $10 \mathrm{mM}$ ethylene glycol tetraacetic acid (EGTA), $2 \mathrm{mM} \mathrm{Na}_{3} \mathrm{VO}_{4}, 2 \mathrm{mM}$ DTT, $50 \mathrm{mM} \mathrm{MgCl}$, $400 \mu \mathrm{M}$ cold ATP and $\left.5 \mu \mathrm{Ci}\left[\gamma_{-}{ }^{32} \mathrm{P}\right] \mathrm{ATP}\right)$. Recombinant p38 $\alpha$ or $\mathrm{p} 38 \beta$ (Millipore) was added to a final concentration of $0.5 \%(\mathrm{wt} / \mathrm{wt})$ total protein. Control and kinase-added samples were assayed at $30^{\circ} \mathrm{C}$ for 1.5 hours. For one-dimensional SDS-PAGE, $5 \times$ Laemmli buffer was added following the assay to $1 \times$, and the sample was electrophoresed. For two-dimensional electrophoresis, 17-cm ReadyStrip immobilised $\mathrm{pH}$ gradient (IPG) strips (Bio-Rad Laboratories, Hercules, CA, USA) were directly rehydrated with labelled lysate diluted in rehydration buffer (7 M urea, $2 \mathrm{M}$ thiourea, 4\% 3-[(3cholamidopropyl)dimethylammonio]-1-propanesulphonate (CHAPS) and 1\% DTT) following the manufacturer's directions. Isoelectric focusing was performed on a PROTEAN IEF Cell (Bio-Rad Laboratories) under the following conditions: $200 \mathrm{~V}$ for 1 hour, $500 \mathrm{~V}$ for 1 hour, 5,000 V ramp for 5 hours and 5,000 V for 80,000 VH. IPG strips were then equilibrated following the manufacturer's instructions and overlaid onto a $12 \%$ SDS-PAGE gel. Following electrophoresis, gels were dried and imaged. For one-dimensional electrophoresis, $100 \mu \mathrm{g}$ of lysate was used per reaction. For two-dimensional electrophoresis, $300 \mu \mathrm{g}$ of lysate was used.

For in vitro substrate identification, assays were performed as described above with the following modifications. A quantity of $1.5 \mathrm{mg}$ of lysate was treated with FSBA, the sample was desalted and $2 \times$ kinase assay buffer was added (40 mM MOPS, $\mathrm{pH}$ 7.2, $50 \mathrm{mM} \beta$-glycerophosphate, $10 \mathrm{mM}$ EGTA, $2 \mathrm{mM} \mathrm{Na}_{3} \mathrm{VO}_{4}, 2 \mathrm{mM}$ DTT, $50 \mathrm{mM} \mathrm{MgCl}$ and $2 \mathrm{mM}$ cold ATP). The sample was then split into three $500-\mu \mathrm{g}$ aliquots, and $5 \mu \mathrm{g}$ of heat-inactivated p38 $\alpha$ was added to the control, $5 \mu \mathrm{g}$ of active p38 $\alpha$ was added to the second aliquot and $5 \mu \mathrm{g}$ of active p38 $\beta$ was added to the third aliquot. The samples were then assayed for 3 hours at $30^{\circ} \mathrm{C}$.

For in vivo substrate identification, assays were performed as above with the following modifications. At 48 hours of differentiation, cells were treated with $5 \mu \mathrm{M}$ of SB 202190 or an equivalent amount of DMSO as vehicle. Twenty-four hours later the cells were lysed in Nonidet P-40 buffer. Lysate $(1 \mathrm{mg})$ from DMSO-treated cells or $2 \times 1 \mathrm{mg}$ of lysate from SB 202190-treated cells was inhibited with FSBA, the samples were desalted and $2 \times$ kinase assay buffer was added to each. A quantity of 5 $\mu \mathrm{g}$ of active $\mathrm{p} 38 \alpha$ was added to one of the lysate aliquots from SB-treated cells. The samples were then assayed for 3 hours at $30^{\circ} \mathrm{C}$.

\section{Dimethyl labelling}

After assaying the samples, they were precipitated by methanol chloroform, then redissolved in $200 \mu \mathrm{l}$ of $8 \mathrm{M}$ urea and $50 \mathrm{mM}$ Tris. $\mathrm{HCl}, \mathrm{pH}$ 8.1, with sonication. The samples were then reduced with $20 \mathrm{mM}$ DTT for 1 hour at $60^{\circ} \mathrm{C}$ and alkylated by $100 \mathrm{mM}$ iodoacetamide for 30 minutes at room temperature in the dark. Subsequently, the samples were diluted to $2 \mathrm{M}$ urea with 50 $\mathrm{mM}$ Tris. $\mathrm{HCl}, \mathrm{pH} 8.1$, and digested with trypsin at a protein-to-trypsin ratio of 50:1 (wt/wt) for 16 hours at $37^{\circ} \mathrm{C}$. Next, the digested samples were acidified to $\mathrm{pH} 2$ using 10\% (vol/vol) formic acid. Dimethyl labelling of 
the samples was performed as reported previously [11] and is described briefly as follows. The acidified peptides were loaded onto C18 solid phase extraction (SPE) columns (50 mg of packing material). After brief washing with $50 \mathrm{mM}$ sodium phosphate buffer, $\mathrm{pH} 7.5,3 \mathrm{ml}$ of light, intermediate and heavy labelling reagents were loaded onto C18 SPE columns trapped with control, p38 $\alpha$ - and p38 $\beta$-labelled samples, respectively. After being washed with $0.1 \%$ ( $\mathrm{vol} / \mathrm{vol}$ ) formic acid, the labelled samples were eluted with $80 \%$ acetonitrile $(\mathrm{ACN})(\mathrm{vol} / \mathrm{vol})$ and $0.1 \%(\mathrm{vol} / \mathrm{vol})$ formic acid, then dried by vacuum centrifugation.

\section{Phosphopeptide enrichment}

Phosphopeptide enrichment by $\mathrm{TiO}_{2}$ was carried out as reported previously [12] with modifications. The dried samples were redissolved with $65 \% \mathrm{ACN} / 2 \%$ trifluoroacetic acid (TFA)/saturated glutamic acid and combined. $\mathrm{TiO}_{2}$ beads suspended in $65 \% \mathrm{ACN} / 2 \%$ TFA/saturated glutamic acid were added into the above samples with a peptide to $\mathrm{TiO}_{2}$ bead ratio of 1:4 (wt/wt). After being nutated for 40 minutes, the $\mathrm{TiO}_{2}$ beads were recovered by centrifugation and washed thoroughly with $65 \%$ ACN/2\% TFA. Finally, the enriched phosphopeptides were eluted with $10 \%$ ( $\mathrm{vol} / \mathrm{vol}$ ) $\mathrm{NH}_{3} \cdot \mathrm{H}_{2} \mathrm{O}$ and dried by vacuum centrifugation.

Online liquid chromatography tandem mass spectrometry analysis

Online liquid chromatography tandem mass spectrometry (LC-MS/MS) analysis was performed as reported previously $[13,14]$ with modifications. The dried sample was redissolved with $0.1 \%$ formic acid and loaded onto a biphasic trap column $(200 \mu \mathrm{m}$ ID $\times 10 \mathrm{~cm} ; 5-\mathrm{cm}$ reversed phase column packed with ReproSil-Pur C18 resin $(5 \mu \mathrm{m}$ at $200 \AA$ A; Dr.Maisch GmbH, AmmerbuchEntringen, Germany) and a 5-cm monolith strong cation exchange (SCX) column). The trapped phosphopeptides were eluted from the trap column onto a C18 tip column $(75 \mu \mathrm{m}$ ID $\times 20 \mathrm{~cm}, 3 \mu \mathrm{m}$ at $200 \AA$; Dr.Maisch $\mathrm{GmbH})$ by a series of salt washes at increasing concentrations $(0,5,10,15,20,25,30,35,40,45,50,55,60$, 70, 80, 90, 100, 150, 200 and 1,000 mM). Each fraction was then separated by reversed phase-based gradient elution and detected using an LTQ Orbitrap XL Fourier transform mass spectrometer (Thermo Scientific, Waltham, MA, USA). The reversed phase gradient was set as follows: $0 \%$ to $5 \% \mathrm{ACN}$ for 2 minutes, $5 \%$ to $30 \%$ ACN for 90 minutes and $30 \%$ to $80 \%$ ACN for 5 minutes. After flushing with $80 \% \mathrm{ACN}$ for 10 minutes, the column was equilibrated with $0.1 \%$ formic acid aqueous solution for 13 minutes. The LTQ Orbitrap XL Fourier transform mass spectrometer was operated in positive ionization mode. A voltage of $1.8 \mathrm{kV}$ was applied. MS and MS/MS spectra were acquired in a data-dependent mode, and one full MS scan was followed by ten MS/ MS scans. The resolution was set at 60,000 at $\mathrm{m} / \mathrm{z} 400$ after accumulation to a target value of 500,000.

\section{Protein identification and quantification}

All MS/MS spectra in one acquired raw file were converted to a single *.mgf file using DTASuperCharge version 2.0a7 (Matrix Science, Boston, MA, USA). The *. mgf file was queried against the International Protein Index mouse database version 3.52 (EMBL-EBI; http:// www.ebi.ac.uk/IPI/IPIhelp.html) using Mascot version 2.1 (Matrix Science). To evaluate the false discovery rate (FDR), reversed sequences were appended to the database. Cysteine residues were searched as a static modification of $+57.0215 \mathrm{Da}$; methionine residues were searched with a variable modification of $+15.9949 \mathrm{Da}$; and serine, threonine and tyrosine residues were searched with a variable modification of +79.9663 Da. Light, intermediate and heavy dimethylation of peptide amino termini and lysine residues were set as variable modifications of $+28.0313 \mathrm{Da},+32.0564 \mathrm{Da}$ and +36.0757 Da, respectively. Peptides were queried using full tryptic cleavage constraints with up to two missed cleavage sites. The mass tolerances were $7 \mathrm{ppm}$ for parent masses and 0.5 Da for fragment masses. Phosphopeptides with a Mascot score $\geq 30$ (rank $1, P \leq 0.05$, bold red required) were selected and quantified (FDR < 0.01). Phosphorylation site localisation and phosphopeptide quantification were performed using a dimethyladapted version of MSQuant version 2.0a81. For each peptide, the putative site of phosphorylation yielding the highest posttranslational modification (PTM) score was accepted (PTM score > 13 required, as described previously [15]). Peptide ratios were obtained by calculating the extracted ion chromatograms of the light, medium and heavy forms of the peptide using the monoisotopic peaks only, and protein ratios were calculated from the average of all quantified peptides. All MSQuant outputs of the same online multidimensional separation were then imported into StatQuant version 1.2.2, and the quantified phosphopeptides were sorted together and exported.

\section{Substrate validation}

$1 \mu \mathrm{g}$ recombinant HSP27 (Enzo Life Sciences, Farmingdale, NY, USA), recombinant Rps27 (Abnova, Taipei City, Taiwan) or recombinant Smad9 (Abnova) were diluted in $30 \mu \mathrm{l}$ of $1 \times$ kinase assay buffer $(20 \mathrm{mM}$ MOPS, pH 7.2, $25 \mathrm{mM} \beta$-glycerophosphate, $5 \mathrm{mM}$ EGTA, $1 \mathrm{mM} \mathrm{Na} \mathrm{VO}_{4}, 1 \mathrm{mM}$ DTT, $25 \mathrm{mM} \mathrm{MgCl} 2,200$ $\mu \mathrm{M}$ cold ATP and $\left.2.5 \mu \mathrm{Ci}\left[\gamma_{-}{ }^{32} \mathrm{P}\right] \mathrm{ATP}\right)$. A quantity of $500 \mathrm{ng}$ of $\mathrm{p} 38 \alpha$ or $\mathrm{p} 38 \beta$ was then added, and the samples were assayed at $30^{\circ} \mathrm{C}$ for 1 hour. Laemmli buffer at 
$5 \times$ concentration was added to $1 \times$ to terminate the assays, then the samples were electrophoresed and the gels were dried and imaged. Peptide assays were performed similarly with $5 \mu \mathrm{g}$ of the following peptides synthesised by Biomatik (Cambridge, ON, Canada): HSP27 S180-APLPKAVTQSAEITIPVTF, HSP27 A180APLPKAVTQAAEITIPVTF, Rps27 S27-KHKKKRLVQ SPNSYFMDVK, Rps27 A27-KHKKKRLVQAPNSYF MDVK, Smad9 T136-NPYHYQRVETPVLPPVLVP and Smad9 A136-NPYHYQRVEAPVLPPVLVP. The frequency logo was generated using WebLogo [16].

\section{Results}

\section{FSBA inhibits endogenous protein kinases}

A substrate-finding approach that works with cell lysate must overcome the obstacle of endogenous protein kinase activity. Lysate contains tens if not hundreds of active kinases, making it difficult to attribute individual phosphorylations that occur during a lysatebased assay to a particular kinase. 5'-4-fluorosulphonylbenzoyladenosine (FSBA) offers a simple solution. FSBA is an ATP analogue that inhibits protein kinases by occupying the ATP binding site and covalently attaching to an invariant lysine [17-20], the fully functionally conserved and so-called catalytic lysine [21]. As FSBA irreversibly occupies the ATP binding site, a bound kinase will permanently lose activity. Treatment of whole-cell C2C12 myoblast lysate with this compound can completely eliminate the endogenous kinase signal present (Figure 1A).

\section{Kinase-specific substrate labelling}

Cell lysate treated with FSBA can be desalted to remove any unbound inhibitor and a pool of protein with no inherent kinase activity is generated. A kinase of interest can then be added with a kinase assay buffer, and any labelling that subsequently occurs is due to the added kinase as opposed to an endogenous one. To specifically label substrates of p38 $\alpha$, a kinase assay buffer containing $\left[\gamma_{-}{ }^{32} \mathrm{P}\right]$ ATP was added to FSBA-treated $\mathrm{C} 2 \mathrm{C} 12$ lysate, along with recombinant $\mathrm{p} 38 \alpha$, and the sample was assayed at $30^{\circ} \mathrm{C}$. Substrates labelled by p38 $\alpha$ appeared as bands following one-dimensional gel electrophoresis or as spots in two-dimensional gel electrophoresis with no contaminating signal from endogenous kinases (Figure $1 \mathrm{~B}$ and Additional file 1 Figure $\mathrm{S} 1$ ). Although this type of approach is excellent for visualising phosphorylation, it is very difficult to identify phosphorylated proteins through spot-picking and MS. We therefore sought an alternative gel- and radioactive-free approach for identifying phosphorylated proteins.

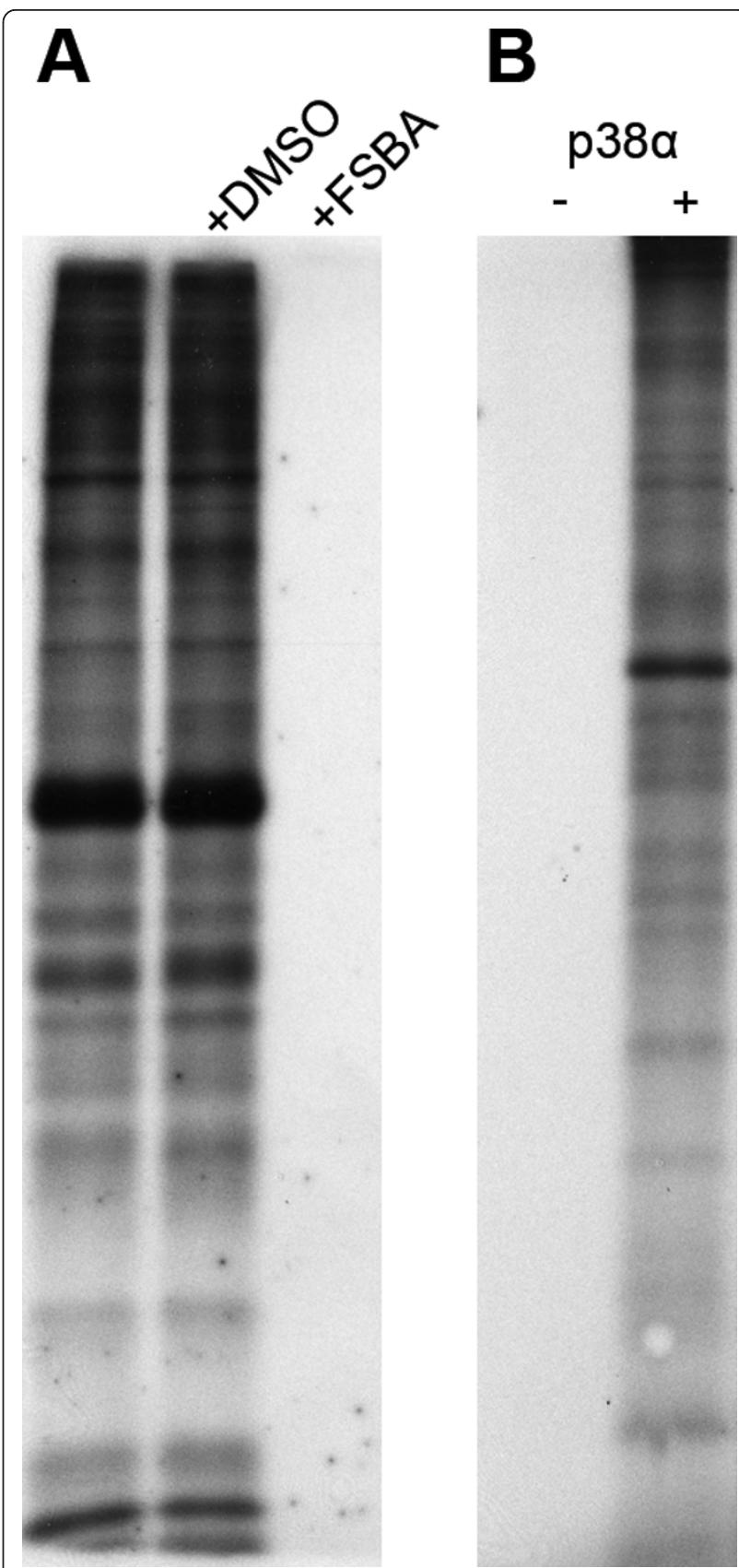

Figure 1 FSBA is a pan-kinase inhibitor that allows for kinasespecific substrate labelling of cell lysate. (A) C2C12 cell lysate was treated with either nothing (lane 1), dimethyl sulphoxide (DMSO) or 5'-4-fluorosulphonylbenzoyladenosine (FSBA) solubilised in DMSO. Subsequently, samples were desalted, kinase assay buffer containing ${ }^{32}$ P- $\gamma$-ATP was added and the samples were assayed for 1.5 hours. Treatment with FSBA abolished the labelling of endogenous protein kinase substrates. (B) After pretreatment of C2C12 cell lysate with FSBA, purified p38 $\alpha$ was added with a kinase assay buffer to specifically label its substrates and visualised using one-dimensional SDS-PAGE or two-dimensional gel electrophoresis (Additional file 1 Figure S1). 


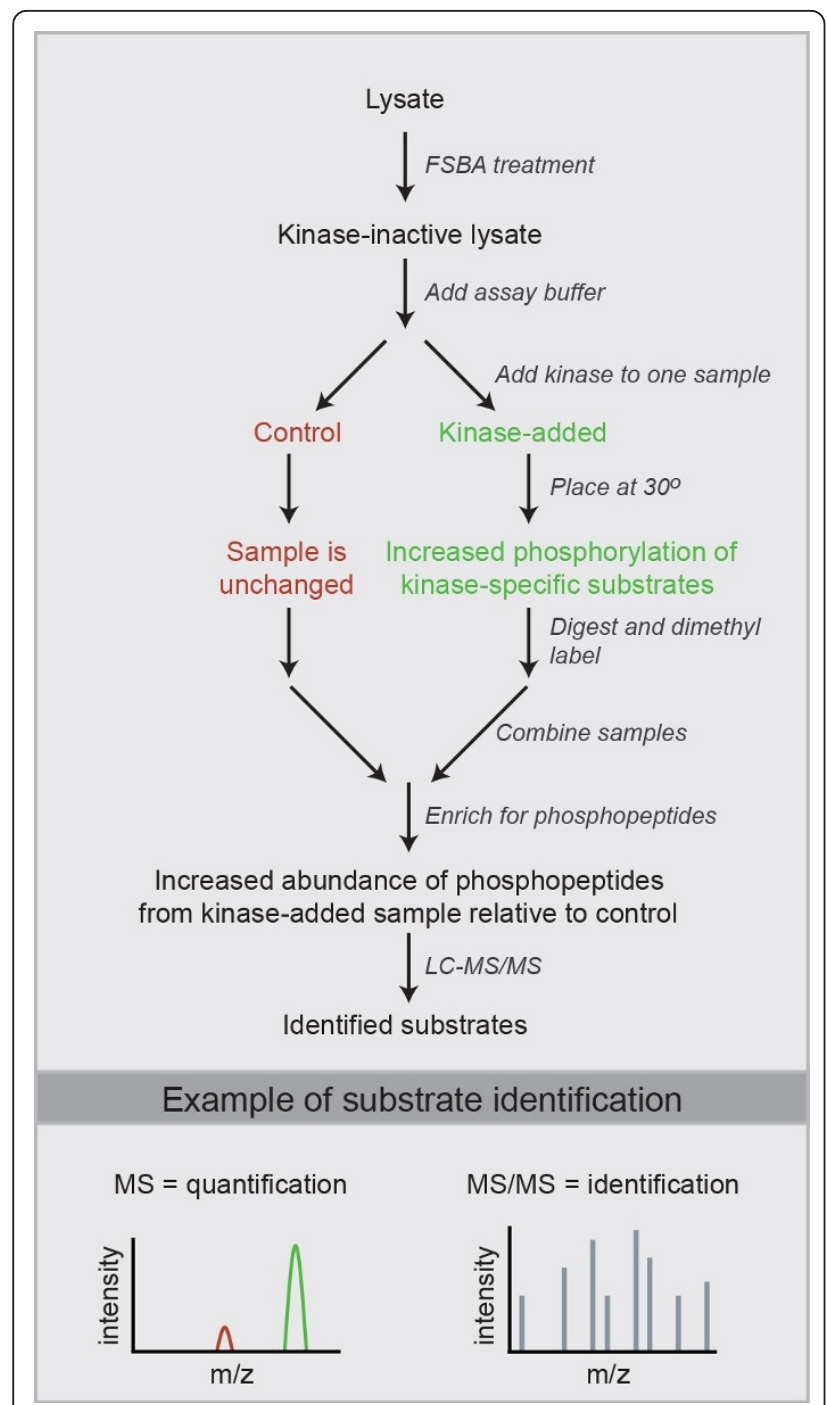

Figure 2 Methodology used to identify in vitro kinase substrates using FSBA and quantitative mass spectrometry. The differential tagging of peptides with dimethyl labels allows for the relative quantification and identification of phosphopeptides simultaneously in a high-mass accuracy mass spectrometer. An example/theoretical substrate identification for the added kinase (green) is shown and is based on the higher intensity of the phosphopeptide in MS.

\section{Quantitative MS coupled with a phosphopeptide enrichment to identify substrates}

The approach we devised to identify substrates is outlined in Figure 2. Cell lysate is treated with FSBA and desalted as described in the previous section. This is followed by the addition of a nonradioactive kinase assay buffer, and the sample is split in two, to one of which is added active kinase (kinase-added). After assaying at $30^{\circ}$ $\mathrm{C}$, the two samples are digested, and peptides from each sample are differentially tagged using isotopomeric dimethyl labels. As a final step before MS, the samples are combined and an enrichment for phosphopeptides is performed using either $\mathrm{TiO}_{2}$ for serine/threonine phosphorylation or a phosphotyrosine antibody for tyrosine phosphorylation. Phosphopeptides are then identified by performing LC-MS/MS, and their relative abundance between samples quantified by the differential dimethyl labelling of peptides. Phosphopeptides that are more abundant in the kinase-added sample are from proteins labelled by the added kinase during the in vitro assay, and by this means substrates can be identified. This approach results not only in substrate identification but also in the identification of the site of phosphorylation. Because up to three samples can be compared using dimethyl labelling, the phosphorylation profile of two kinases (plus a control) can be compared in a single experiment.

We began our initial in vitro substrate-finding procedure by treating $1.5 \mathrm{mg}$ of $\mathrm{C} 2 \mathrm{C} 12$ lysate with FSBA. For the assay, the sample was split into three equal parts, with active p38 $\alpha$ and $\beta$ added to the second and third samples, respectively. The rationale behind comparing p $38 \alpha$ with p38 $\beta$ was to identify specific p38 $\alpha$ phosphorylations that might explain why p $38 \beta$ cannot compensate for the loss of $\mathrm{p} 38 \alpha$ in differentiating myoblasts. In total, 387 unique serine/threonine phosphopeptides were identified (Additional file 1 Table S1). A histogram of their relative abundance ratios (p38 /control) is shown in Additional file 1 Figure S2. A threefold increase in the abundance ratio was selected as a cutoff for high-confidence in vitro substrates as this ratio is beyond the range of inherent variability, and 158 phosphorylation sites from 94 different proteins showed at least a threefold increase in the p38 $\alpha$-assayed sample relative to the control. The list of $\mathrm{p} 38 \alpha$ phosphorylation sites is presented in Additional file 1 Table S2. We identified five previously known substrates (caldesmon, histone H2B, Psmd1, SAKS1 and Smad3) and eighty-nine that were previously unknown. Three of these previously unknown targets were validated to determine if the technique was discovering true in vitro $\mathrm{p} 38 \alpha$ substrates. Recombinant forms of these three proteins could be phosphorylated in vitro by $\mathrm{p} 38 \alpha$ (Figure $3 \mathrm{~A}$ ), and a validation of peptides confirmed the site of phosphorylation (Figure 3B). After aligning substrates on their phosphorylation sites, we found that a consensus phosphorylation motif was present in many substrates, although it was not an absolute requirement (Figure 3C). The motif contains a proline immediately downstream from the target serine or threonine and an aliphatic residue two residues upstream. This motif is in agreement with that previously described for p38 [22], providing further support for our substrate-finding approach. 


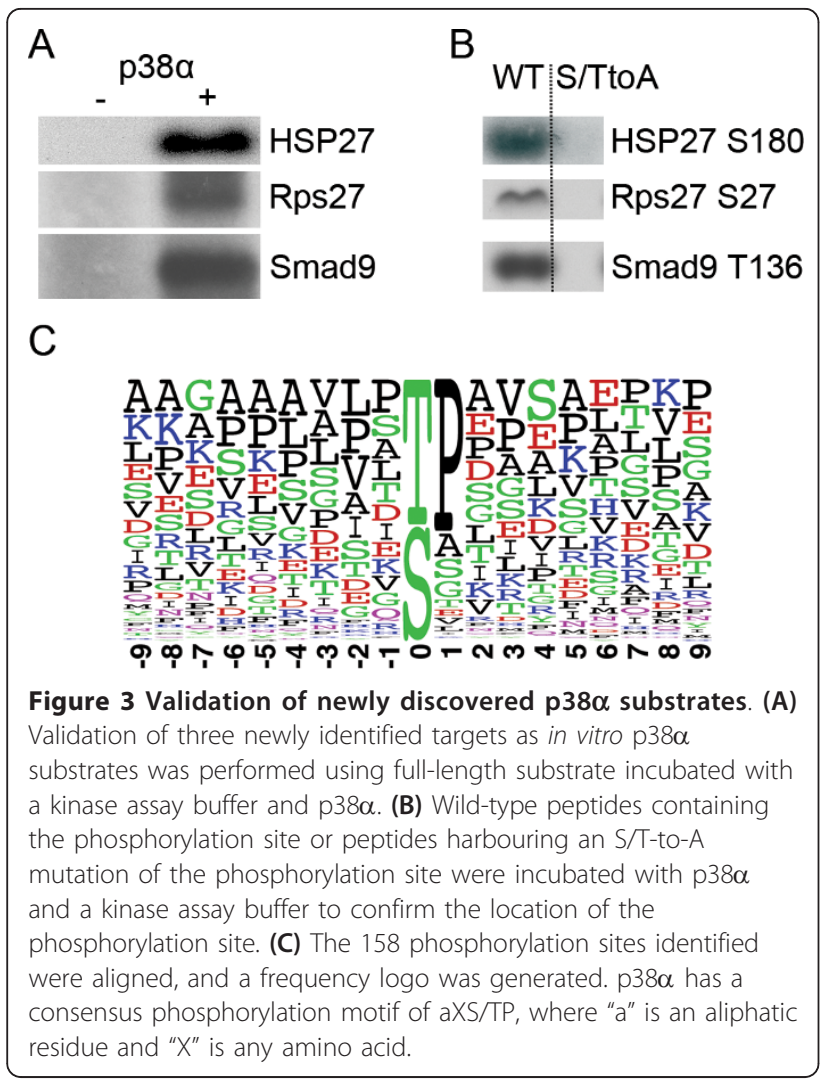

Substrate specificity does not distinguish $p 38 \alpha$ and $p 38 \beta$ We first assayed p38 $\alpha$ and p38 $\beta$ on cell lysate using the radioactive approach and were surprised to see no obvious differences in the substrate banding patterns produced by the two isoforms (Figure 4A). Consistent with this observation, of the $158 \mathrm{p} 38 \alpha$ phosphorylations identified using the quantitative approach, none appeared to be specific to this isoform. The 158 quantitative values for the $\mathrm{p} 38 \alpha$ phosphorylations are plotted from highest to lowest in Figure $4 \mathrm{~B}$ (blue line for $\mathrm{p} 38 \alpha$ ). The red line represents the corresponding p38 $\beta$ values. Although $\mathrm{p} 38 \alpha$ and $\mathrm{p} 38 \beta$ showed apparent differences in preference, they had very similar overall profiles. There were only four phosphorylations that fell above the threefold cutoff for p $38 \alpha$, whereas for $\mathrm{p} 38 \beta$ they were well below. However, the values were still positive for $\mathrm{p} 38 \beta$, suggesting that these could be real phosphorylations but there is simply less confidence in them. To determine if these might represent specific phosphorylations, we performed in vitro assays with either $\mathrm{p} 38 \alpha$ or p38 $\beta$ using purified substrate for one candidate. The purified substrate was the 40 S ribosomal protein S27 (Rps27), and both p38 isoforms were able to phosphorylate this protein at the same site (Figure 4C and 4D).

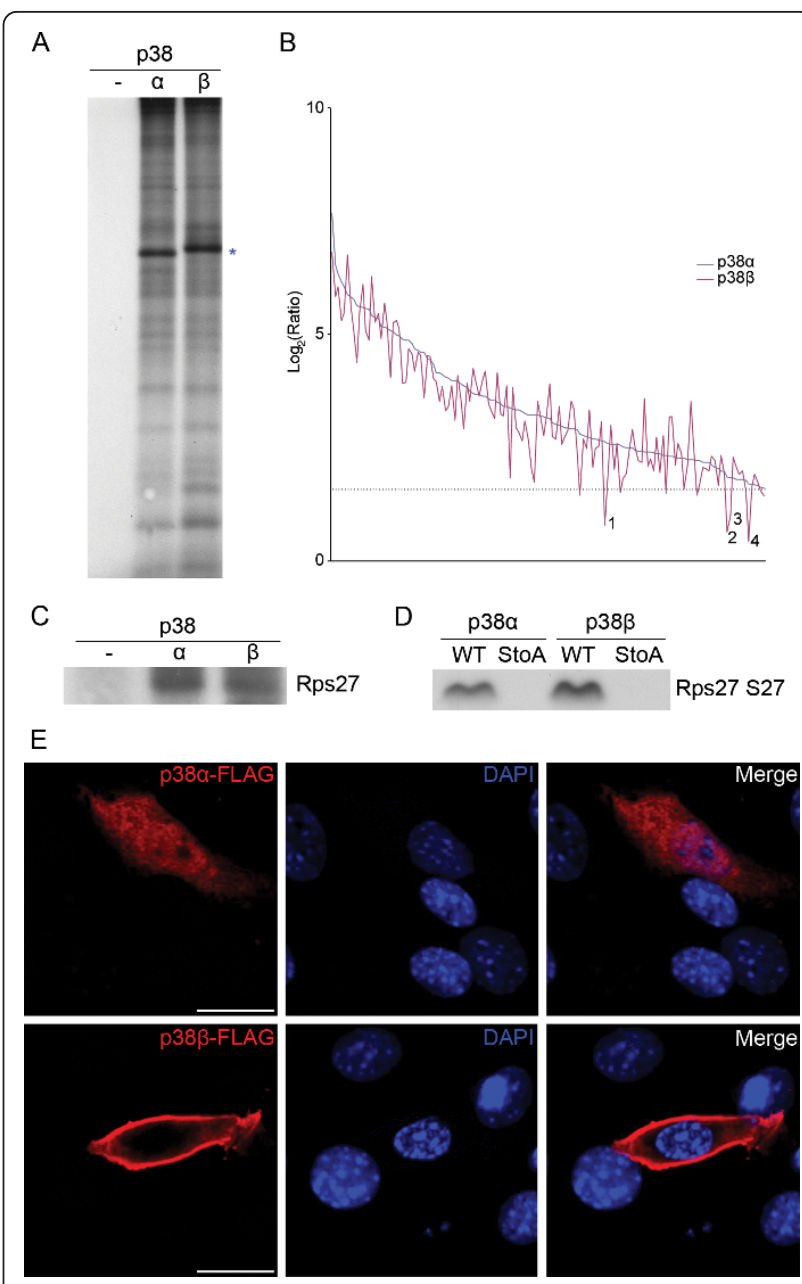

Figure 4 Localisation, not substrate specificity, distinguishes p38 $\alpha$ from p38 $\beta$. (A) FSBA-treated C2C12 cell lysate was incubated with a kinase assay buffer and p38 $\alpha, p 38 \beta$ or no kinase as a control. Both isoforms produced similar banding patterns. The prominent bands marked with the asterisks in each of the p38 $\alpha$ and p38 $\beta$ lanes represent autophosphorylation of the added recombinant kinase. (B) The quantitative values for all 158 identified p38 $\alpha$ phosphorylations are plotted in blue on a $\log _{2}$ scale, with the corresponding values for $p 38 \beta$ shown in red. The dashed line represents the fold cutoff for accepted substrates. Four p38 $\beta$ phosphorylations fell appreciably below the fold cutoff (point 2 corresponds to serine 27 of the 40 S ribosomal protein S27-Rps27). (C) Incubation of $p 38 \alpha$ or $p 38 \beta$ with purified Rps 27 and a kinase assay buffer. (D) Incubation of $p 38 \alpha$ or $p 38 \beta$ with a peptide from Rps 27 containing serine 27 (or mutation of serine 27 to alanine) and a kinase assay buffer. (C) and (D) demonstrate that serine 27 of Rps 27 is not a specific p38 $\alpha$ phosphorylation site. (E) FLAG-tagged p38 $\alpha$ or p38 $\beta$ were transfected into C2C12 cells, and at 48 hours of differentiation immunofluorescence staining for FLAG was performed. p38 $\alpha$ has a ubiquitous distribution, whereas p38 $\beta$ is found solely at the cell periphery. Cells were imaged using a Zeiss LSM 510 META confocal microscope (Carl Zeiss Microlmaging $\mathrm{GmbH}$, Jena, Germany). Scale bar $=20 \mu \mathrm{m}$. 
Therefore, none of the 158 phosphorylations found for p38 $\alpha$ appear to be specific to this isoform.

If substrate specificity does not distinguish the two p38 isoforms, and yet p38 $\beta$ is unable to compensate for the loss of p38 $\alpha$, there must be an alternative characteristic that discriminates them. An obvious possibility is cellular localisation. If $\mathrm{p} 38 \alpha$ and $\mathrm{p} 38 \beta$ localise differently within the cell, then p38 $\beta$ would simply be unable to

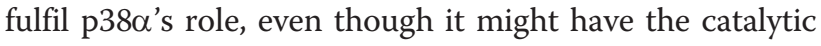
potential to do so. To study this, we overexpressed FLAG-tagged $\mathrm{p} 38 \alpha$ and $\mathrm{p} 38 \beta$ in $\mathrm{C} 2 \mathrm{C} 12$ cells and assessed their localisation during differentiation (Figure $4 \mathrm{E})$. Whereas $\mathrm{p} 38 \alpha$ has a ubiquitous localisation pattern, p38 $\beta$ is found only at the periphery of the cell. p38 $\alpha$ therefore has access to a substrate pool that $\mathrm{p} 38 \beta$ does not, highlighting a major reason why p $38 \beta$ cannot compensate for the loss of $\mathrm{p} 38 \alpha$.

\section{Identification of novel in vivo $\mathrm{p} 38 \alpha$ substrates}

Although the approach we have outlined can identify in vitro kinase substrates, such in vitro approaches will also turn up irrelevant substrates that are phosphorylated only because of the absence of the appropriate cellular context. For example, we identified just over 400 phosphorylation sites in the screen described above, 158 of which are in vitro p38 targets. If these numbers are representative, it suggests that p38 could be responsible for approximately $40 \%$ of all cellular phosphorylations in differentiating myoblasts, a number that seems unlikely, given that there are about 500 mouse and human kinases [23].

To overcome the drawbacks associated with in vitro substrate identification, we modified the approach to allow for the identification of relevant, direct in vivo substrates (outlined in Figure 5). For our purposes, differentiating $\mathrm{C} 2 \mathrm{C} 12$ cells were treated either with the p38 inhibitor SB 202190 or with DMSO as vehicle prior to lysis. SB inhibitor or vehicle treatment began at 48 hours of differentiation, and the cells were lysed 24 hours later. The 48-hour time point was chosen because of our interest in identifying novel functions for p38 $\alpha$ during the middle stages of myoblast differentiation. Myogenic gene activation occurs within the first 48 hours of differentiation [24] and is followed by cell fusion, sarcomere formation and other processes. If differentiating $\mathrm{C} 2 \mathrm{C} 12$ myoblasts are treated with a p38 inhibitor at 48 hours, there is a reduction in cell fusion and overall differentiation (Additional file 1 Figure S3), indicating that there is a requirement for long-term p38 activity for efficient myogenesis beyond the initial stage of myogenic gene activation, possibly both for maintaining such gene activation and for fusion-related processes. Following cell lysis, a 1-mg aliquot was taken from the lysate of vehicle-treated cells and two 1-mg

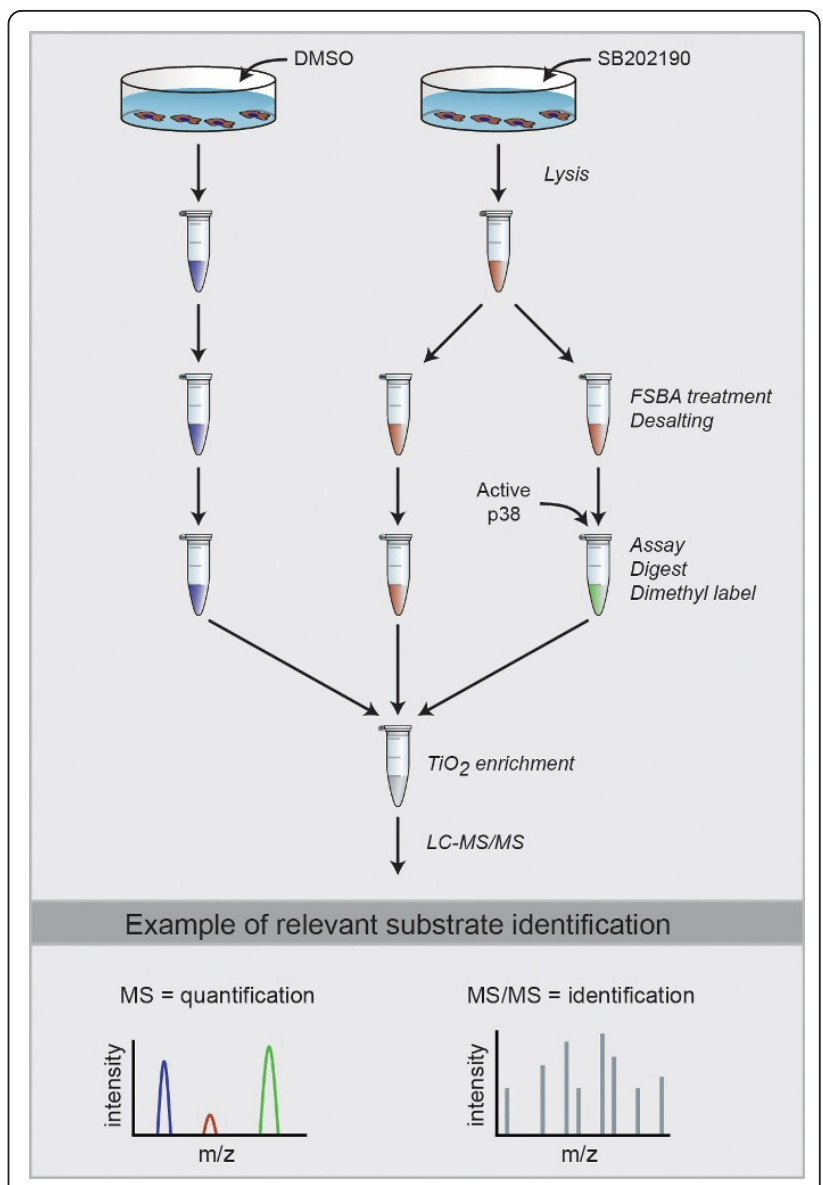

Figure 5 Methodology used to identify in vivo kinase substrates using FSBA and quantitative MS. In vivo substrates are identified based on the higher phosphopeptide intensity in MS for both the vehicle-treated (blue) and kinase-added (green) samples. A higher phosphopeptide abundance in MS for the vehicle-treated (blue) sample relative to the inhibitor-treated (red) sample indicates a phosphorylation site regulated by the kinase of interest in vivo. A higher phosphopeptide abundance for the kinase-added (green) sample relative to the inhibitor-treated (red) sample indicates a phosphorylation site directly targeted by the kinase in vitro.

aliquots were taken from the lysate of inhibitor-treated cells. All three aliquots were treated with FSBA and desalted to remove unbound FSBA and SB inhibitor, and a kinase assay buffer was added to each. Active p38 $\alpha$ was added to one of the inhibitor-treated aliquots, and the samples were assayed at $30^{\circ} \mathrm{C}$. Following the assay, the samples were digested, dimethyl-labelled and phosphopeptides enriched as described above. What we sought to identify were phosphorylation sites that decreased on inhibitor treatment and could be elevated back up by direct in vitro p38 $\alpha$ labelling of SB inhibitortreated lysate. These would be direct phosphorylation sites regulated by $\mathrm{p} 38 \alpha$ in vivo.

By using this approach, we identified a total of 717 phosphorylation sites (Additional file 1 Table S3), 73 of 
Table 1 Newly discovered in vivo $\mathrm{p} 38 \alpha$ substrates

\begin{tabular}{|c|c|c|}
\hline Genes & Protein names & Sites \\
\hline Ahnak & Neuroblast differentiation-associated protein AHNAK & S4906 \\
\hline IWs 1 & Protein IWS1 homolog & $\begin{array}{l}\text { S183, } \\
\text { S185 }\end{array}$ \\
\hline Grp78 & 78 kDa glucose-regulated protein & T649 \\
\hline Pgrme & $\begin{array}{l}\text { Membrane-associated progesterone receptor } \\
\text { component } 1\end{array}$ & S181 \\
\hline $\operatorname{Prd} \times 6$ & Peroxiredoxin 6 & T93 \\
\hline Ranbp2 & E3 SUMO ${ }^{a}$ protein ligase RanBP2 & S2505 \\
\hline
\end{tabular}

aSUMO, small ubiquitin-like modifier.

which showed a threefold decrease following SB inhibitor treatment, and seven of these sites were direct p38 $\alpha$ phosphorylation sites (that is, showed at least a threefold increase in the p38 $\alpha$-labelled sample relative to the lysate from inhibitor-treated cells). In contrast to the pure in vitro approach, which suggested that approximately $40 \%$ of all cellular phosphorylations might be p38 target sites, the numbers derived from the in vivo study suggest that the actual level is closer to about $1 \%$. The seven in vivo sites (on six substrates) that we identified are listed in Table 1.

The substrate Iws 1 is a largely nuclear protein involved in several processes, such as chromatin remodelling and mRNA export $[25,26]$, functions with which p38 has previously been associated. Ranbp2 localises predominantly to the nuclear pore complex and is critical for myotube formation [27]. The other four substrates are cytoplasmic proteins without known or suggested nuclear functions (Ahnak, Grp78, Pgrmc and Prdx6). On the basis of fractionations and Western blot analysis, we found that $\mathrm{p} 38 \alpha$ was indeed present in the cytoplasm during differentiation (Figure 6A), which is in agreement with the immunofluorescence staining of FLAG-tagged $\mathrm{p} 38 \alpha$. The levels of phosphorylated $\mathrm{p} 38$, the active form, increased in the cytoplasm with differentiation (Figure 6A and Additional file 1 Figure S4), suggesting that $\mathrm{p} 38 \alpha$ might play an important role there. Validation of the phospho-p38 antibody is shown in Additional file 1 Figure S5. Further fractionation of the cytoplasm revealed that p38 $\alpha$ and phospho-p38 were present only in the cytosolic fraction (Figure 6B), meaning that all four of the in vivo cytoplasmic phosphorylation sites we identified would be accessible to p38 $\alpha$. Using Scansite [28], we found that five of the six substrates contained one or more predicted D domains, MAPK docking domains found on many in vivo substrates (D domain sites and scores are listed in Additional file 1 Table S4). We next used Genemania [29] to identify previously known associations between these substrates and the p38 activation pathway we recently reviewed and outlined [30]. Four of the substrates have previously known associations with this pathway (Figure

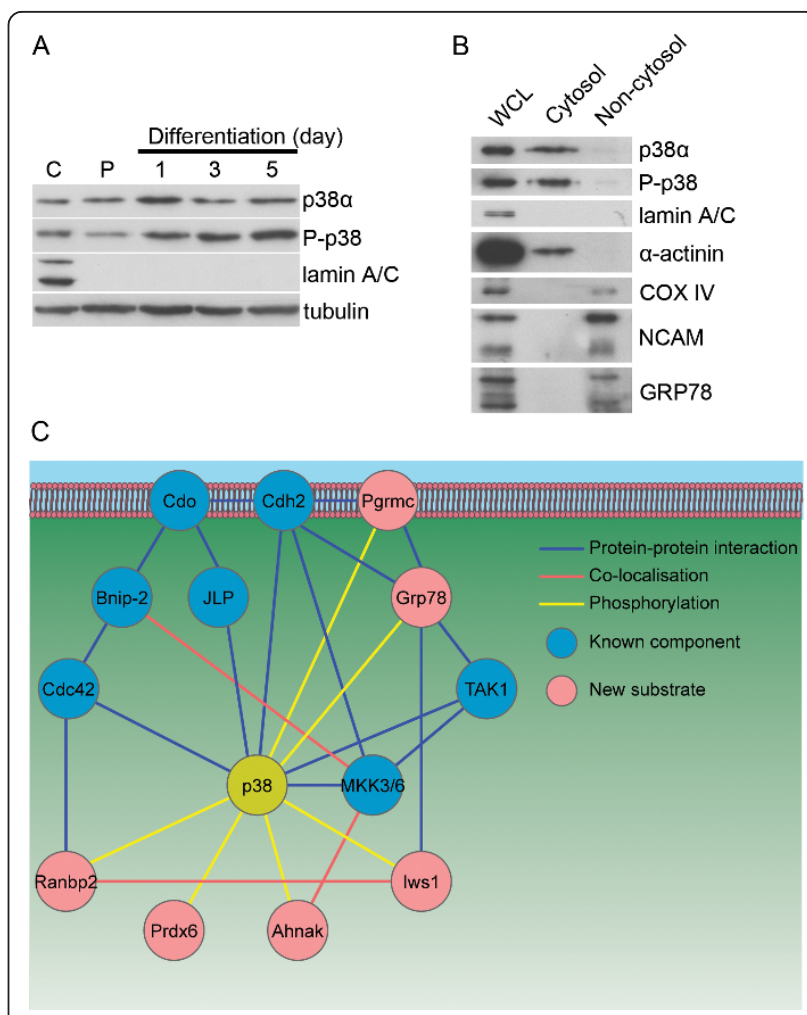

Figure 6 Cytoplasmic characterization of $\mathrm{p} 38 \alpha$ during $\mathrm{C} 2 \mathrm{C} 12$ cell differentiation. (A) $\mathrm{C} 2 \mathrm{C} 12$ cells were fractionated over a differentiation time course. C, control whole-cell lysate; P, proliferating lysate. Western blotting for phospho-p38 shows a clear increase in the cytoplasm as differentiation proceeds. Nuclei were removed in the initial step of fractionation, and lamin A/C was used to demonstrate that there were no contaminating nuclei in cytoplasmic extracts. Quantification of phospho-p38 expression is shown in Additional file 1 Figure S4. (B) After 48 hours of differentiation, $\mathrm{C} 2 \mathrm{C} 12$ cells were lysed and the cytoplasmic fraction was collected and further fractionated into cytosolic (including the cytoskeleton) and noncytosolic fractions. Nuclear marker: lamin A/C; cytoskeletal marker: $\alpha$-actinin; mitochondrial marker: COX IV; membrane marker: neural cell adhesion molecule (NCAM); endoplasmic reticulum marker: GRP78. (C) Interconnections between the $138 \alpha$ activation pathway and newly discovered in vivo substrates. Proteins previously associated with p38 $\alpha$ in its activation pathway are indicated as blue nodes. New substrates are indicated as red nodes. Edge colouring indicates the type of association between nodes.

$6 \mathrm{C})$, providing additional support that these targets are relevant and that their phosphorylation could be critical for pathway function.

\section{Discussion}

We have described here a simple technique for kinase substrate finding that uses whole-cell lysate, can identify sites of phosphorylation in addition to the protein phosphorylated, has the ability to identify both in vivo and in vitro substrates, and can be used to compare the in vitro substrate specificity of two kinases in the same 
experiment. Performing the assay with $\mathrm{p} 38 \alpha$ and $\mathrm{p} 38 \beta$ revealed that, although differences in preference are apparent, there are no obvious phosphorylation sites specific to $\mathrm{p} 38 \alpha$. However, a major characteristic that distinguishes $\mathrm{p} 38 \alpha$ from $\mathrm{p} 38 \beta$ during myoblast differentiation is localisation, with $\mathrm{p} 38 \alpha$ located ubiquitously throughout the cell while p $38 \beta$ is found only at the cell periphery. We also have shown that $\mathrm{p} 38 \alpha$ can phosphorylate several cytosolic phosphorylation sites in vivo and that this may be a critical but previously unknown function for it. These results demonstrate the utility of the substrate screening technique we have developed and how its use not only can find proteins phosphorylated by a kinase of interest but also can answer particular questions and propose novel avenues of research.

The technique we have developed has several advantages over existing substrate finding approaches. It can provide direct substrate identifications and information on in vivo relevance in a single experiment. Whole-cell lysate can be used as a source of candidate substrates, allowing screens to be performed on samples of specific relevance to the area of interest instead of on protein or peptide arrays. Our approach for eliminating endogenous kinase activity in lysate is nondenaturing, decreasing the likelihood of false-positive and false-negative substrate phosphorylations that would result from the heatinactivating approach that others have employed [31,32]. At the same time, the recombinant kinase used in the assay does not require mutation or unnatural ATP analogues as other approaches do [33], making the technique applicable to any kinase that can be made and purified in an active form. Although we used dimethyl labelling for quantitative MS, the technique is fully compatible with iTRAQ, which allows up to eight samples to be compared in a single experiment, meaning that simultaneous in vivo substrate identification and kinase comparisons can be performed. Radioactivity and gel work are not required, but can be used to visualise phosphorylations and make qualitative comparisons between kinases on one-dimensional gels. The lysate requirements are also relatively low; 1.5 to $3 \mathrm{mg}$ were used in these assays, which may make the technique difficult to employ with some primary cells lines, but it is easily applicable to most secondary cell lines and to tissues as well. We have treated several different lysate types with FSBA, and complete inhibition of endogenous kinase activity occurred in all, meaning that our approach is likely universally applicable. In this study our approach for identifying in vivo substrates utilised an inhibitor, but it is more versatile than that, and can be applied to study phosphorylations triggered by a specific stimulus (using stimulated versus unstimulated cells for lysate pools) without requiring a specific inhibitor be available. Finally, although we have performed the in vivo approach on unfractionated lysate, when combined with fractionation prior to LC-MS/MS, the number of substrates identified could be much greater than what we have demonstrated in principle here.

As mentioned, a major advantage of the technique presented here is that it can be used to compare the substrate profiles of two or more kinases, and we used this to study the substrate specificity of the p38 $\alpha$ and $\beta$ isoforms. However, we were unable to identify any phosphorylations that were specific to $\mathrm{p} 38 \alpha$. There are apparent differences in preference for substrates between $\mathrm{p} 38 \alpha$ and $\mathrm{p} 38 \beta$, which could be functionally relevant. Assuming that $\mathrm{p} 38 \beta$ had the same ubiquitous localisation pattern as $\mathrm{p} 38 \alpha$, a low preference for certain critical myogenic phosphorylations could result in a difference in cell behaviour if p38 $\beta$ were the only isoform present. However, it seems likely that differentiation would still occur, but possibly at a reduced rate or in a compromised way. This is not the case, as p $38 \beta$-containing myoblasts that lack $\mathrm{p} 38 \alpha$ fail to differentiate at all $[7-9,34]$. Rather, we believe what truly distinguishes the two isoforms is their localisation. p38 $\alpha$ has a known critical role in the nucleus, and our results suggest that the same may be true for the cytoplasm; therefore, $\mathrm{p} 38 \beta$ would be unable to compensate because it is found solely at the periphery of the cell. A similar distinction exists for two other closely related kinases, focal adhesion kinase (FAK) and proline-rich tyrosine kinase 2 (PYK2) [35]. In fibroblasts, FAK localises to focal adhesions, whereas PYK2 has a perinuclear distribution. PYK2, which has a kinase domain $60 \%$ identical to that of FAK, can compensate for the loss of FAK provided it has a focal adhesion targeting sequence. Together these results suggest that rather than substrate specificity, it is other characteristics, in these cases localisation, that distinguish closely related kinases. Whether the same holds true for the entire kinase family is an intriguing question.

In addition to p38 $\alpha$ 's known role in regulating gene expression at the onset of myoblast differentiation, our results suggest that it is likely to have a cytosolic role as well, possibly in regulating its own pathway. We have found that $\mathrm{p} 38 \alpha$ is present in the cytosol, active p38 increases in the cytoplasm with differentiation, p38 $\alpha$ can phosphorylate several cytosolic proteins, three of the cytosolic proteins contain predicted D domains, and connections between these proteins and the p38 $\alpha$ activation pathway have been previously reported. Together these results suggest a previously unrecognised role for p38 $\alpha$ in the cytosol.

\section{Conclusions}

While the role of the p38 $\alpha$ MAPK during myoblast differentiation has been studied extensively with regard to 
gene regulation, our evidence suggests that this kinase is likely involved in other processes as well. The differentiation of myoblasts into a mature myotube involves extensive morphological and functional changes that p38 $\alpha$ might regulate, both through the initiation of a myogenic gene program and through direct phosphorylation and functional modification of cytosolic proteins. No one has previously been able to identify a p38 $\alpha$-specific substrate, and our large-scale screen suggests these may exist only within the context of cellular localisation. In addition, the substrate screening technique we have developed should serve as a useful tool for studying the other kinases known to be involved in myogenesis, as well as the hundreds of other protein kinases that exist.

\section{Additional material}

Additional file 1: Figures S1 through S5 and Tables S1 through S4.

\section{Acknowledgements}

JDRK was supported by a Vanier Canada Graduate Scholarship, a Canadian Institutes of Health Research (CIHR) Canada Graduate Scholarship and a Multiple Sclerosis Society of Canada (MSSC) Studentship. LAM holds the Mach Gaensslen Chair in Cardiac Research and was funded by CIHR. ACG is a Canada Research Chair in Functional Proteomics and the Lea Reichmann Chair and is funded by CIHR grant MOP-84314. DF acknowledges a Canada Research Chair in Proteomics and Systems Biology as well as grants from the Natural Sciences and Engineering Research Council of Canada and the JLouis Lévesque Foundation. RK holds a University Health Research Chair at the University of Ottawa and was supported by grants from CIHR and the MSSC.

\section{Author details}

'Regenerative Medicine Program, Ottawa Hospital Research Institute, 501 Smyth Road, Ottawa, ON, K1H 8L6, Canada. ${ }^{2}$ Department of Cellular and Molecular Medicine, University of Ottawa, 451 Smyth Road, Ottawa, ON, K1H 8M5, Canada. ${ }^{3}$ Ottawa Institute of Systems Biology, University of Ottawa, 451 Smyth Road, Ottawa, ON, K1H 8M5, Canada. ${ }^{4}$ Department of Biochemistry, Microbiology and Immunology, University of Ottawa, 451 Smyth Road, Ottawa, ON, K1H 8M5, Canada. ${ }^{5}$ CAS Key Lab of Separation Sciences for Analytical Chemistry, Dalian Institute of Chemical Physics, Chinese Academy of Sciences, Dalian, 116023, China. ${ }^{6}$ Department of Medicine, University of Ottawa, 451 Smyth Road, Ottawa, ON, K1H 8M5, Canada. ${ }^{7}$ Samuel Lunenfeld Research Institute, Mount Sinai Hospital, 600 University Avenue, Toronto, ON, M5G 1X5, Canada. ${ }^{8}$ Department of Molecular Genetics, University of Toronto, 1 King's College Circle, Toronto, ON, M5S 1A8, Canada. ${ }^{9}$ Current address: Samuel Lunenfeld Research Institute, Mount Sinai Hospital, 600 University Avenue, Toronto, ON, M5G 1X5, Canada. ${ }^{10}$ Current address: Department of Cancer Biology, Dana-Farber Cancer Institute, 450 Brookline Avenue, and Department of Genetics, Harvard Medical School, 77 Avenue Louis Pasteur, Boston, MA 02115, USA.

\section{Authors' contributions}

JDRK and RK conceived of and designed the project. JDRK conceived of the substrate-finding technique. RT assisted JDRK with the implementation of the substrate-finding technique. RECL performed two-dimensional gel work and assisted JDRK with the development of the radioactive approach. FW assisted with quantitative MS analysis and phosphopeptide validation. $A B$ assisted with cell cultures. All other experiments and analysis were performed by JDRK. JDRK wrote the paper, and RK revised and edited it. HZ supervised FW. LAM supervised RECL and gave advice on project design. DF supervised RT and FW, and DF, TP and ACG provided MS facilities and expertise. RK supervised JDRK. All authors read and approved the final manuscript.

\section{Competing interests}

The authors declare that they have no competing interests.

Received: 22 August 2011 Accepted: 6 March 2012

Published: 6 March 2012

\section{References}

1. Berwick DC, Tavaré JM: Identifying protein kinase substrates: hunting for the organ-grinder's monkeys. Trends Biochem Sci 2004, 29:227-232.

2. Johnson SA, Hunter T: Kinomics: methods for deciphering the kinome. Nat Methods 2005, 2:17-25.

3. Manning BD, Cantley LC: Hitting the target: emerging technologies in the search for kinase substrates. Sci STKE 2002, 2002:pe49.

4. Sopko R, Andrews BJ: Linking the kinome and phosphorylome: a comprehensive review of approaches to find kinase targets. Mol Biosyst 2008, 4:920-933.

5. Holt $L$, Tuch BB, Villén J, Johnson AD, Gygi SP, Morgan DO: Global analysis of Cdk1 substrate phosphorylation sites provides insights into evolution. Science 2009, 325:1682-1686.

6. Lluís F, Perdiguero E, Nebreda AR, Muñoz-Cánoves P: Regulation of skeletal muscle gene expression by p38 MAP kinases. Trends Cell Biol 2006, 16:36-44.

7. Li Y, Jiang B, Ensign WY, Vogt PK, Han J: Myogenic differentiation requires signalling through both phosphatidylinositol 3-kinase and p38 MAP kinase. Cell Signal 2000, 12:751-757.

8. Perdiguero E, Ruiz-Bonilla V, Gresh L, Hui L, Ballestar E, Sousa-Victor P, Baeza-Raja B, Jardí M, Bosch-Comas A, Esteller M, Caelles C, Serrano AL, Wagner EF, Muñoz-Cánoves P: Genetic analysis of p38 MAP kinases in myogenesis: fundamental role of $\mathrm{p} 38 \mathrm{a}$ in abrogating myoblast proliferation. EMBO J 2007, 26:1245-1256.

9. Wang $H, X u$, Xiao F, Jiang $Y$, Wu Z: Involvement of the p38 mitogenactivated protein kinase $\alpha, \beta$, and $\gamma$ isoforms in myogenic differentiation. Mol Biol Cell 2008, 19:1519-1528.

10. Enslen H, Raingeaud J, Davis RJ: Selective activation of p38 mitogenactivated protein (MAP) kinase isoforms by the MAP kinase kinases MKK3 and MKK6. J Biol Chem 1998, 273:1741-1748.

11. Boersema PJ, Raijmakers R, Lemeer S, Mohammed S, Heck AJ: Multiplex peptide stable isotope dimethyl labeling for quantitative proteomics. Nat Protoc 2009, 4:484-494.

12. $L i Q R$, Ning ZB, Tang JS, Nie S, Zeng R: Effect of peptide-to-TiO ${ }_{2}$ beads ratio on phosphopeptide enrichment selectivity. J Proteome Res 2009, 8:5375-5381.

13. Wang F, Dong J, Jiang X, Ye M, Zou H: Capillary trap column with strong cation-exchange monolith for automated shotgun proteome analysis. Anal Chem 2007, 79:6599-6606.

14. Wang F, Chen R, Zhu J, Sun D, Song C, Wu Y, Ye M, Wang L, Zou H: A fully automated system with online sample loading, isotope dimethyl labeling and multidimensional separation for high-throughput quantitative proteome analysis. Anal Chem 2010, 82:3007-3015.

15. Olsen JV, Blagoev B, Gnad F, Macek B, Kumar C, Mortensen P, Mann M: Global, in vivo, and site-specific phosphorylation dynamics in signaling networks. Cell 2006, 127:635-648.

16. Crooks GE, Hon G, Chandonia JM, Brenner SE: WebLogo: a sequence logo generator. Genome Res 2004, 14:1188-1190.

17. Hashimoto E, Takio K, Krebs EG: Amino acid sequence at the ATP-binding site of CGMP-dependent protein kinase. J Biol Chem 1982, 257:727-733.

18. Kamps MP, Taylor SS, Sefton BM: Direct evidence that oncogenic tyrosine kinases and cyclic AMP-dependent protein kinase have homologous ATP-binding sites. Nature 1984, 310:589-592.

19. Russo MW, Lukas TJ, Cohen S, Staros JV: Identification of residues in the nucleotide binding site of the epidermal growth factor receptor/kinase. J Biol Chem 1985, 260:5205-5208.

20. Zoller MJ, Nelson NC, Taylor SS: Affinity labeling of CAMP-dependent protein kinase with $p$-fluorosulfonylbenzoyl adenosine: covalent modification of lysine 71. J Biol Chem 1981, 256:10837-10842.

21. Knight JD, Qian B, Baker D, Kothary R: Conservation, variability and the modeling of active protein kinases. PLoS One 2007, 2:e982. 
22. Schwartz D, Gygi SP: An iterative statistical approach to the identification of protein phosphorylation motifs from large-scale data sets. Nat Biotechnol 2005, 23:1391-1398.

23. Manning G, Whyte DB, Martinez R, Hunter T, Sudarsanam S: The protein kinase complement of the human genome. Science 2002, 298:1912-1934.

24. Andrés V, Walsh K: Myogenin expression, cell cycle withdrawal, and phenotypic differentiation are temporally separable events that precede cell fusion upon myogenesis. J Cell Biol 1996, 132:657-666.

25. Diebold ML, Koch M, Loeliger E, Cura V, Winston F, Cavarelli J, Romier C: The structure of an Iws $1 /$ Spt 6 complex reveals an interaction domain conserved in TFIIS, Elongin A and Med26. EMBO J 2010, 29:3979-3991.

26. Yoh SM, Cho H, Pickle L, Evans RM, Jones KA: The Spt6 SH2 domain binds Ser2-P RNAPII to direct Iws1-dependent mRNA splicing and export. Genes Dev 2007, 21:160-174.

27. Asally M, Yasuda Y, Oka M, Otsuka S, Yoshimura SH, Takeyasu K, Yoneda Y: Nup358, a nucleoporin, functions as a key determinant of the nuclear pore complex structure remodeling during skeletal myogenesis. FEBS J 2011, 278:610-621.

28. Obenauer JC, Cantley LC, Yaffe MB: Scansite 2.0: Proteome-wide prediction of cell signaling interactions using short sequence motifs. Nucleic Acids Res 2003, 31:3635-3641.

29. Warde-Farley D, Donaldson SL, Comes O, Zuberi K, Badrawi R, Chao P, Franz M, Grouios C, Kazi F, Lopes CT, Maitland A, Mostafavi S, Montojo J, Shao Q, Wright G, Bader GD, Morris Q: The GeneMANIA prediction server: biological network integration for gene prioritization and predicting gene function. Nucleic Acids Res 2010, , 38 Web server: W214-W220.

30. Knight JD, Kothary R: The myogenic kinome: protein kinases critical to mammalian skeletal myogenesis. Skelet Muscle 2011, 1:29.

31. Huang SY, Tsai ML, Chen GY, Wu CJ, Chen SH: A systematic MS-based approach for identifying in vitro substrates of PKA and PKG in rat uteri. $J$ Proteome Res 2007, 6:2674-2684.

32. Troiani S, Uggeri M, Moll J, Isacchi A, Kalisz HM, Rusconi L, Valsasina B: Searching for biomarkers of Aurora-A kinase activity: identification of in vitro substrates through a modified KESTREL approach. J Proteome Res 2005, 4:1296-1303.

33. Blethrow JD, Glavy JS, Morgan DO, Shokat KM: Covalent capture of kinasespecific phosphopeptides reveals Cdk1-cyclin B substrates. Proc Natl Acad Sci USA 2008, 105:1442-1447.

34. Ruiz-Bonilla V, Perdiguero E, Gresh L, Serrano AL, Zamora M, Sousa-Victor P, Jardí M, Wagner EF, Muñoz-Cánoves P: Efficient adult skeletal muscle regeneration in mice deficient in $p 38 \beta, p 38 \gamma$ and $p 38 \delta$ MAP kinases. Cell Cycle 2008, 7:2208-2214.

35. Klingbeil CK, Hauck CR, Hsia DA, Jones KC, Reider SR, Schlaepfer DD Targeting Pyk2 to $\beta 1$-integrin-containing focal contacts rescues fibronectin-stimulated signaling and haptotactic motility defects of focal adhesion kinase-null cells. J Cell Biol 2001, 152:97-110.

doi:10.1186/2044-5040-2-5

Cite this article as: Knight et al: A novel whole-cell lysate kinase assay identifies substrates of the p38 MAPK in differentiating myoblasts. Skeletal Muscle 2012 2:5.

\section{Submit your next manuscript to BioMed Central and take full advantage of:}

- Convenient online submission

- Thorough peer review

- No space constraints or color figure charges

- Immediate publication on acceptance

- Inclusion in PubMed, CAS, Scopus and Google Scholar

- Research which is freely available for redistribution

Submit your manuscript at www.biomedcentral.com/submit
Biomed Central 